\title{
ANALYSIS OF HEMATOLOGICAL PARAMETERS IN PATIENTS WITH ISCHEMIC STROKE AT DMCH, LAHERIASARAI, BIHAR
}

\section{Pathology}

\author{
Dr. MeghaJha
}

M.B.B.S., M.D. (Pathology),

Tutor, DepartmentofPathology, Darbhanga Medical College, Laheriasarai, Bihar.

\begin{tabular}{ll}
\hline $\begin{array}{l}\text { Dr. Hari Shankar } \\
\text { Mishra* }\end{array}$ & M.B.B.S., M.D. (Pathology), Associate Professor, Department of Pathology, Darbhanga \\
Medical College, Laheriasarai, Bihar. *Corresponding Author
\end{tabular}

Dr. [Prof.] Ajit Kumar Chaudhary

M.B.B.S., M.D. (Pathology),Professor and Head of Department, Department of Pathology, Darbhanga Medical College, Laheriasarai, Bihar.

Young Scientist (DST) Institute of Post-Graduate Medical Education and Research, A.J.C. Bose Road, Kolkata-700020, West Bengal, India

\section{ABSTRACT}

Background: Hematological parameters are major indicator of ischemic stroke. Hematological parameters and stroke incidence have not been investigated in local population. Objective: The present study was designed to assess whether hematological parameters play an important role in ischemic stroke patients. Methodology: For this purpose a cross-sectional study was done at Department of Pathology,Darbhanga Medical College andHospital, Laheriasarai, Bihar from January 2020 to August 2020. A total of 150subjects were enrolled in Medicine Department and referred to Pathology Department for various hematological test.Patients divided into two groups, control $(\mathrm{n}=50)$ and ischemic stroke subjects $(\mathrm{n}=100)$. Data regarding risk factors was collected through questionnaire. Their hematological parameters such as WBCs count, RBCs count, haemoglobin concentration, HCT, MCV, MCH and PLT count were assessed by hematology analyzer. Statistical analysis was done by using SPSS (version 13). Result: Mean age of control and ischemic stroke group was $61.40 \mathrm{y} \pm 1.33$ and $63.8 \mathrm{y} \pm 1.36$ respectively with non-significant difference between the groups. Among the ischemic stroke subjects, $73 \%$ of the subjects were suffering from hypertension, $53 \%$ reported diabetes, $41 \%$ had heart disease, $39 \%$ had family history of stroke, $32 \%$ were smokers and $46 \%$ use high cholesterol food. The WBCs count, MCV, MCH and HCT were found significantly higher in ischemic stroke subjects when compared with control group while the significant decrease was observed in RBCs count and hemoglobin concentration. PLT count increased in ischemic stroke subjects as compared to control group. Conclusion: It was concluded that in ischemic stroke patients hematological parameters were greatly altered.

\section{KEYWORDS}

WBCs, RBCs, Platelets, ischemic stroke

\begin{abstract}
Introduction
Stroke, a growing epidemic, is an important cause of mortality and disability worldwide. It remains the third leading cause of death and the leading cause of severe disability in the United States, Europe and portions of Asia in young. Stroke is a sudden loss of neurologic function resulting from focal disturbance of cerebral blood flow due to ischemia or hemorrhage in elderly people. Acute ischemic stroke represents a common and challenging disease with increasing morbidity despite decreasing mortality. Ischemic Stroke, in which blood flow to the brain is blocked by blood clots or fatty deposits called plaque in blood vessel linings. It is also caused by occlusion of an artery in the neck or in the brain, depriving a part of the brain of its nutrients, glucose and oxygen. When an ischemic stroke occurs, the blood supply to the brain is interrupted, and brain cells are deprived of the glucose and oxygen they need to function.
\end{abstract}

Hypertension, carotid artery stenosis, atrial fibrillation and certain other cardiac conditions, cigarette smoking, diabetes mellitus, dyslipidemia, sickle cell disease, poor diet, physical inactivity, and obesity are well-established risk factors for ischemic stroke. Less wellestablished risk factors include alcohol and drug abuse, the metabolic syndrome, oral contraceptive use, sleep-disordered breathing, migraine and hypercoagulability. The greatest stroke risk, however, occurs in those with previous transient ischemic attack or previous stroke. Many studies have highlighted the prognostic importance of various laboratory parameters like blood sugar, total leukocyte count, and erythrocyte sedimentation rate (ESR) in stroke patients. Our aim was to characterize the clinical hematological parameters and their role in ischemic stroke.

\section{Materials and methods}

This was a cross sectional study on 150 subjects, which are divided into two groups. In ischemic stroke group $(\mathrm{n}=100)$ and control group $(n=50)$. Questionnaire were filled from both groups in which the various question asked were regarding age, gender, occupation, body weight, height, hypertension (if the person's blood pressure was persistently above $140 / 90 \mathrm{mmHg}$, blood sugar(diabetes), cardiac disease, taking high cholesterol food. Smoking was considered as a risk factor if a person smokes more than 10 cigarettes a day.

Exclusion criteria for all subjects were trauma, surgery or severe liver disease, renal failure, cancer, chronic inflammatory or infectious condition at study entry. We did not exclude patients with an infection after stroke or patients with family history of stroke. For healthy control subjects, any vascular diseases or risk factors were additional exclusion criteria. Subjects with a history of myocardial infarction or stroke were excluded from the control group. In stroke patients, blood samples were taken within 24hours. Blood samples were collected by venipuncture. Blood was stored in EDTA lined tubes that prevent the blood clotting, and analyzed by hematological apparatus.

\section{Statistical analysis}

In this study confidence interval (CI) were calculated at the $95 \%$ level and the data were recorded in SPSS software version 13, and analyzed using statistical method Independent T-test. Demographic data was presented as Mean \pm S.E.M. Prevalence was determined by percentages. For all statistical analysis, a value of $\mathrm{P} \leq 0.05$ was considered to indicate significant variation.

\section{Results}

A total of 150 blood samples were collected and divided into two groups, control and ischemic stroke group. To better understand the hematological parameters in ischemic stroke subjects, they were compared with the normal healthy individuals from the same population. The ischemic stroke group comprised of 100subjects and control group consisted of 50healthy subjects. The age range of ischemic stroke subjects was 40-90y. Controls and ischemic stroke subjects were further categorized by gender. In ischemic stroke group $44 \%$ were females and $56 \%$ were males. Similarly, in control group $52 \%$ were females and $48 \%$ were males. Each subject filled a questionnaire including questions about age, weight, height and risk factors associated with stroke. Prevalence of Cerebrovascular risk factors such as cigarette smoking, hypertension, heart diseases, atrial fibrillation and diabetes were assessed in ischemic stroke patients presented in Table 1. The mean age of control and ischemic stroke group was $61.4 \pm 1.33$ years and $63.3 \pm 1.36$ years respectively with no 
significant difference (Table 2). Non-significant difference was observed in mean BMI of control was $24.3(\mathrm{~kg} / \mathrm{m} 2) \pm 0.38$ and ischemic group $25.6(\mathrm{~kg} / \mathrm{m} 2) \pm 0.42$. The mean values of Hematological parameters were presented in Table 3. Significant difference between the mean values of Red blood Cells (RBCs), White blood cells (WBCs), mean corpuscular hemoglobin (MCH), hematocrit (HCT) and haemoglobin $(\mathrm{Hb})$ was observed.

Table 1 : Frequency of stroke risk factors in ischemic Stroke Subjects

\begin{tabular}{|c|c|c|}
\hline Factors & Yes\% & No\% \\
\hline Hypertension & $73 \%$ & $27 \%$ \\
\hline Diabetes mellitus & $53 \%$ & $47 \%$ \\
\hline Heart disease & $41 \%$ & $59 \%$ \\
\hline Atrial fibrillation & $38 \%$ & $62 \%$ \\
\hline Smoking & $32 \%$ & $68 \%$ \\
\hline Family History & $39 \%$ & $61 \%$ \\
\hline Use of alcohol & $10 \%$ & $90 \%$ \\
\hline
\end{tabular}

Table 2 :Demographic characteristics of control and ischemic stroke group

\begin{tabular}{|c|c|c|c|c|}
\hline Sl. No. & Factors & Control & Ischemic & $\begin{array}{c}\text { P value (T- } \\
\text { test) }\end{array}$ \\
\hline 1. & Age (years) & $61.40 \pm 1.33$ & $63.8 \pm 1.36$ & 0.37 \\
\hline 2. & Weight $(\mathrm{kg})$ & $67.1 \pm 0.99$ & $70.6 \pm 1.12$ & 0.04 \\
\hline 3. & Height $(\mathrm{m})$ & $1.65 \pm 0.01$ & $1.66 \pm 0.01$ & 0.8 \\
\hline 4. & BMI $(\mathrm{kg} / \mathrm{m} 2)$ & $24.05 \pm 0.38$ & $25.6 \pm 0.42$ & 0.02 \\
\hline
\end{tabular}

Table 3 :Prevalence of gender and hematological parameters in ischemic stroke group and control

\begin{tabular}{|c|c|c|c|}
\hline Factors & Control group & $\begin{array}{c}\text { Ischemic stroke } \\
\text { group }\end{array}$ & P-value \\
\hline Male $\%$ & $48 \%$ & $56 \%$ & \\
\hline Female $\%$ & $26 \%$ & $44 \%$ & \\
\hline $\mathrm{RBC} \times 106 / \mathrm{mm} 3$ & $4.75 \pm 0.56$ & $3.64 \pm 0.65$ & $0.0001^{* *}$ \\
\hline $\mathrm{WBC} \times 106 / \mathrm{mL}$ & $8.04 \pm 0.36$ & $12.21 \pm 0.51$ & $0.0001^{* *}$ \\
\hline $\begin{array}{c}\text { PLT } \times 103 \\
\text { platelets } / \mathrm{ml}\end{array}$ & $269.22 \pm 10.06$ & $295.43 \pm 8.91$ & $0.07(\mathrm{NS})$ \\
\hline $\mathrm{MCV}(\mathrm{fL})$ & $85.65 \pm 0.92$ & $86.93 \pm 1.14$ & 0.46 \\
\hline $\mathrm{MCH}(\mathrm{pg})$ & $28.04 \pm 0.23$ & $34.32 \pm 0.73$ & $0.0001^{* *}$ \\
\hline $\mathrm{HCT}(\%)$ & $47.13 \pm 0.56$ & $39.11 \pm 0.93$ & $0.0001^{* *}$ \\
\hline $\mathrm{Hgb}(\mathrm{g} / \mathrm{dL})$ & $13.48 \pm 0.28$ & $9.10 \pm 0.22$ & 0.0001 \\
\hline
\end{tabular}

*Significant $\mathrm{P} \leq 0.05,{ }^{* *}$ Highly Significant $\mathrm{P} \leq 0.01$

\section{Discussion}

The subjects included in our study were of single ethnicity and from same area; ischemic stroke was significantly associated with low count of hematological parameters. It was observed that there was an association with ischemic stroke and hematological parameters as significant difference in hematological parameters was observed in ischemic subjects as compared to control subjects. Ischemic stroke has no geographic and socio-economic boundaries. Worldwide, 15 million people suffer a stroke each year. Recent evidence suggests that white blood cells exert a role in the pathogenesis of brain ischemic damage. Age and gender specific prevalence of risk factors in patients with first ever ischemic stroke was observed in china. They concluded that prevalence of ischemic stroke was higher in both male and female patients $<80$ years of age. Non significant difference was observed in mean age of ischemic stroke patients and control similar study was reported by Bill et al.

It was demonstrated in our study that WBC significantly increased in ischemic stroke patients as compared to control group subjects. Present results are similar to Kazmierski et al. The increased in WBC count during ischemic stroke may be due to the mobilization of the leukocyte marginal pool as an inflammatory response to the ischemic damage to brain parenchyma. Immediately after an ischemic stroke, an increased expression of a wide range of cytokines and chemokine precedes WBC infiltration into the ischemic tissue. This study reported increased PLT count in ischemic stroke as compared to control group. The result implies that enhanced platelet responsiveness and persistent systemic activation of circulating platelets is a critical mechanism in the pathophysiology of acute cerebrovascular disease. Platelets play a critical role in acute and chronic inflammation. Platelet activation plays a pivotal role in the pathogenesis of thrombotic vascular disorders, such as ischemic stroke and TIA.

Results of our study coincided with investigation of Ahmed et al. His preliminary evaluation related to the ranges of hematological variable showed that WBC and PLT count increased in the same manner as in our study. MCV values also increased in ischemic stroke group. In our study, RBC count, $\mathrm{Hb}$ and $\mathrm{HCT}$ are in line of previous finding. In present study RBC count decreased in ischemic stroke group as compared with control in accordance with other study. During ischemic stroke erythrocyte undergoes oxidative and proteolytic changes resulting in a changed cellular rheology and inflammatory process. In thromboembolic ischemic stroke patients $92 \%$ of abnormal erythrocyte are present. 18 In the blood smear of more than 60stroke patients, RBC have a changed shape showing membrane pseudopodia like extensions and some produce elongated membrane extensions that might be associated and form interaction with the fibrin fibers during clot formation.

Hemoglobin concentration was significantly low in ischemic stroke group as compared to the control subjects. The mechanism by which lower hemoglobin associates with stroke was unknown. However, one possible explanation is through its influence on energy supply. Hemoglobin carries $98 \%$ of the total blood oxygen, yet within one standard deviation of the normal range that the level may vary by as much as $20 \%$. The result was significantly impaired in the ischemic brain with limited ability of the brain to increase the extraction of available oxygen. Available evidence in animal models of ischemic stroke suggests that lower hemoglobin reduces the threshold for ischemia and results in larger infarct volumes. HCT level significantly increased in ischemic stroke group as compared to control subjects. In 1972, the Framingham study showed that a higher level of hemoglobin might be a risk factor for cerebral infarction and since then, several clinical and clinic pathological observations indicated that high hematocrit (Hct) may be associated with the occurrence of cerebral ischemia.

The Framingham study and several clinical pathological observations showed that high levels of hemoglobin or Hct might be associated with the occurrence of cerebral ischemia. Elwood et al. reported that mortality over a three-year period was related to Hct in 18,740women. However, experimental studies showed that when Hct was as low as $30 \%$ or below or hemoglobin was $9 \mathrm{~g} / 100 \mathrm{ml}$ or below, a compensatory mechanism would be no longer suffice to prevent cerebral hypoxia. Further investigation and follow-up studies should be performed to evaluate whether the alteration of hematological parameters is associated with an increased risk for the occurrence of cerebral ischemic event.

\section{Conclusion}

It was concluded that hematological parameters potentially able to impair cerebral microcirculation, in particular with a previous cerebral ischemic event. The presences of persistently altered status of hematological parameters in patients with a recent cerebral ischemic event indicate that this aspect of hematological parameters can be considered a simple inflammatory reaction occurring during the development of ischemic damage.

\section{References}

1. Ahmad C, Zahr TG, Fereshteh A. Preliminary Evaluations Related tothe Ranges of Hematological and Biochical Variables in HospitalizedPatients with Stroke. International journal of preventive medicine.2013;4(2):347-352.

Astrup J, Seisjo BK, Symon L. Thresholds in cerebral ischemia - theischemic penumbra. Stroke. 1981;12(6):723-725.

Bill O, Zufferey P, Faouzi M, Michel P. Sever Stroke: Patients profileand Predictors of favourable outcome. Journal of thrombosis andhaemastosis. 2013;11(1):92-99.

Dexter F, Hindman BJ. Effect of haemoglobin concentration on brainoxygenation in focal stroke: a mathematical modelling study. Br JAnaesth. 1997;79(3):346-351. Elwood PC, Waters, WE, Benjamin IT, et al. Mortality and anaemia inwomen. Lancet. 1974;1:891-894.

6. Fan FC, Chen RYZ, Schuessler GB, et al. Effects of hematocritvariations on regional hemodynamics and oxygen transport in the dog.Am J Physiol. 1980;238(4):545-552. hemodynamics and oxygen transport in the dog.Am JPhysiol. 1980;238(4):545-552.
Goldstein LB, Adams R, Alberts MJ, et al. Primary prevention of ischemicstroke: Goldstein LB, Adams R, Alberts MJ, et al. Primary prevention of ischemicstroke:
guideline from the American heart association/American strokeassociation stroke council: cosponsored by the atherosclerotic peripheralvascular disease interdisciplinary working group; cardiovascularnursing council; clinical cardiology council; nutrition, physical activity,and metabolism council; and the quality of care and outcomes researchinterdisciplinary working group: the american academy of neurologyaffirms the value of this guideline. Stroke. 2006;37(6):1583-1633.

8. Hankey GJ. Stroke: how large a public health problem and how can theneurologist help? Arch Neurol. 1999;56(6):748-754

Hickey JV. Anticoagulants and antiplatelet agents in acute ischemic stroke: Report of the Joint Stroke Guideline Development Committee of the American Academy of 
Neurology and the American Stroke Association (A division of the American Heart Association). The clinical practice of neurological and neurosurgical nursing. 2003;147:621-625.

10. Kannel WB, Gordon T, Wolf PA, et al. Hemoglobin and the risk ofcerebral infarction: The Framingham study. Stroke. 1972;3(4):409-420.

11. Kazmierski R, Guzik P, Ambrosius W. Predictive value of white bloodcell count on admission for in-hospital mortality in acute stroke patients.ClinNeurol Neurosurgery. 2004;107(1):38-43.

12. Kochanek PM, Hallenbeck JM. Polymorph nuclear leucocytes andmonocytes/macrophages in the pathogenesis of cerebral ischemia andstroke. Stroke. 1992;23(9):1367-1379.

13. Kolominsky RPL, Heuschmann PU. Incidence, etiology and Long-termprognosis of stroke. FortschrNeurolPsychiatr. 2002;70(12):657-662.

14. Lo EH, Dalkara T, Moskowitz MA. Mechanisms, challenges andOpportunities in stroke. Nat Rev Neuroscience. 2003;4(5):399-415.

15. Metcalf D. The hematopoietic regulators: redundancy or subtlety?Blood. 1993;82(12):3515-3523.

16. Moftakhar D, Means RT, Glader B, et al. Rodgers GM. Disorders of Red Cells. Wintrobe's Clinical Hematology. 2012;26:109-111.

17. Myers AM, Saunders CR, Chalmer DG. The haemoglobin level of fitelderly people. Lancet. 1968;2(7562):261-263.

18. Naess H, Tatlisumak T, Korv J. Stroke in the young. Stroke. 2012;83:656-913.

19. Pantoni L, Sarti C, Inzitari D. Cytokines and cell adhesion moleculesin cerebral ischemia: experimental bases and therapeutic perspectives.Arteriosclerosis ischemia: experimental bases and therapeutic perspectives.Arteriosclerosis

20. Perls T, Kunkel LM, Puca AA. The genetics of exceptional humanlongevity. The American journal of Stroke. 2002;50(2):359-368.

21. Sacco RL, Adams R, Albers G, et al. Guidelines for prevention of strokein patients with ischemic stroke or transient ischemic attack: a statementfor healthcare professionals from the American heart association/American stroke association council on stroke: cosponsored by thecouncil on cardiovascular radiology and intervention: the Americanacademy of neurology affirms the value of this guideline. Stroke.2006:37(2):577-617.

22. Smith NM, Pathansali R, Bath PM. Platelets and stroke. Vasc Med.1999;4(3):165-172.

23. Thomas DJ, Duboulay GH, Marshall J. Effect of haematocrit on cerebralblood-flow in Thomas DJ, Duboulay GH, Marshall J. Effect of haematocrit on cerebralblood-flow in
man. Lancet. 1977;2(8045):941-943.

24. Townsend N, Wickramasinghe K, Bhatnagar P, et al. Coronary heartdisease statistics 2012. British Heart Foundation. 2012;98:72.

25. Uchiyama S, Yamazaki M, Hara Y. Alterations of platelet, coagulation, and fibrinolysis markers in patients with acute ischemic stroke. SeminThromb. Hemost. 1997;23(6):535-541

26. Xiao YY, Yan L, Jie L, et al. Age- and Gender-Specific Prevalenceof Risk Factors in Patients with First-Ever Ischemic Stroke in China.Hindawi Publishing Corporation Stroke Research and Treatment.2012;1:1-6. 